\title{
Treatment of Dyspepsia, Heartburn, and Related Symptoms with Gastricumeel Compared to Proton Pump Inhibitors: A Prospective Reference- Controlled Observational Study
}

\author{
Robbert van Haselen $^{a} \quad$ Konstantin Cesnulevicius $^{b}$

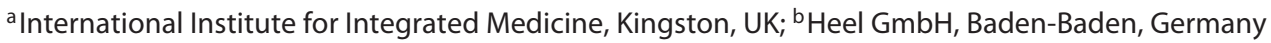

\section{Keywords}

Dyspepsia · Gastritis · Gastroesophageal reflux disease ·

Gastricumeel · Proton pump inhibitors

\begin{abstract}
Background: Dyspepsia and heartburn are extremely common conditions, thus a search for safe and effective treatment alternatives is justified. Objectives: To demonstrate the noninferiority of Gastricumeel (Ga6) in terms of effectiveness and safety to proton pump inhibitors (PPIs) in the treatment of patients with dyspepsia and/or heartburn. Methods: Prospective, comparative, observational cohort study. Patients with dyspepsia or heartburn were treated either with Ga6 or with PPIs as monotherapy during approximately 6 weeks. The intensity of eight symptoms was assessed as well as overall condition, treatment compliance and tolerability, and any adverse drug reactions. Adjustment for covariates was done via the calculation of propensity scores in logistic regression. Results: A total of 640 patients (447 Ga6, 193 PPIs) from 48 German general practices participated. More than half the patients had suspected acute gastritis and around $40 \%$ of patients had heartburn. Adjusted between-treatment difference scores of changes in the intensity of the eight assessed symptoms were within the bounds for noninferiority of Ga6 compared to PPIs. Effectiveness ratings were comparable; compliance and tolerability were rated better in the Ga6 group. Conclusion: It is worth considering Ga6 as a safe and effective treatment option in the management of dyspepsia and heartburn.
\end{abstract}

(c) 2020 The Author(s)

Published by S. Karger AG, Basel

karger@karger.com www.karger.com/cmr

Karger ${ }^{\prime \prime}$

BOPEN ACCESS
(C) 2020 The Author(s)

Published by S. Karger AG, Basel

This is an Open Access article licensed under the Creative Commons Attribution-NonCommercial-4.0 International License (CC BY-NC) (http://www.karger.com/Services/OpenAccessLicense), applicable to the online version of the article only. Usage and distribution for commercial purposes requires written permission.

\begin{abstract}
Gastricumeel im Vergleich zu
Protonenpumpenhemmern in der Behandlung von

Dyspepsie, Sodbrennen und damit einhergehenden Symptomen: eine prospektive, referenzkontrollierte Beobachtungsstudie
\end{abstract}

\section{Schlüsselwörter}

Dyspepsie · Gastritis · Refluxkrankheit · Gastricumeel · Protonenpumpenhemmer

\section{Zusammenfassung}

Hintergrund: Dyspepsie und Sodbrennen sind sehr weitverbreitete Beschwerden, daher ist eine Suche nach sicheren und wirksamen Behandlungsalternativen gerechtfertigt. Ziele: Nachweis der Nichtunterlegenheit von Gastricumeel (Ga6) gegenüber Protonenpumpenhemmern hinsichtlich der Wirksamkeit und Sicherheit in der Behandlung von Patienten mit Dyspepsie und/oder Sodbrennen. Methoden: Prospektive, vergleichende, beobachtende Kohortenstudie. Patienten mit Dyspepsie oder Sodbrennen wurden für etwa 6 Wochen entweder mit Ga6 oder mit Protonenpumpenhemmern in Monotherapie behandelt. Die Schwere von acht Symptomen wurde ebenso beurteilt wie der Allgemeinzustand, die Therapietreue, die Verträglichkeit und etwaige unerwünschte Arzneimittelwirkungen. Eine Anpassung für Kovariaten erfolgte nach der Propensity-Score-Methode im Rahmen einer logistischen Regression. Ergebnisse: Insgesamt 640 Patienten (447 Ga6, 193 Protonenpumpenhemmer) aus 
48 allgemeinärztlichen Praxen in Deutschland nahmen teil. Bei mehr als der Hälfte der Patienten bestand Verdacht auf akute Gastritis; rund $40 \%$ litten unter Sodbrennen. Die adjustierten Behandlungsdifferenz-Scores für die Veränderung der Schwere der acht betrachteten Symptome lagen innerhalb des Rahmens für die Nichtunterlegenheit von Ga6 gegenüber Protonenpumpenhemmern. Die Wirksamkeitsergebnisse waren vergleichbar; Therapietreue und Verträglichkeit wurden in der Ga6-Gruppe besser beurteilt. Schlussfolgerung: Ga6 verdient als sichere und wirksame Behandlungsoption bei Dyspepsie und Sodbrennen in Betracht gezogen zu werden.

() 2020 S. Karger AG, Basel

\section{Introduction}

Gastritis is a condition in which the stomach mucosa is inflamed. It may present as acute or chronic, erosive or nonerosive disease. Common causes of gastritis include Helicobacter pylori infection, damage to the gastric mucosa caused by, e.g., nonsteroidal anti-inflammatory drugs, alcohol, stress, or an autoimmune response (e.g., Crohn's disease, sarcoidosis) [1]. Gastritis is often asymptomatic. If the gastritis is symptomatic, common symptoms are upper abdominal discomfort or pain, nausea, and vomiting. Epidemiological data confirm a high prevalence of gastritis and dyspeptic symptoms. For instance, the prevalence of functional dyspepsia is $12 \%$ in the USA and $8 \%$ in Canada and the UK [2].

Functional dyspepsia is classified in accordance with the Rome IV criteria based on the most bothersome clinical symptoms, notably epigastric pain, postprandial fullness, and early satiation [3]. Whilst the Rome IV criteria have helped to better define the condition, its symptomatic expression remains variable, and there is also overlap with irritable bowel syndrome in a significant number of patients [4]. Pyrosis, also called heartburn, designates a burning sensation in the retrosternal area caused by regurgitation of gastric acid (gastric reflux) into the esophagus. Heartburn and acid regurgitation are two cardinal symptoms of gastroesophageal reflux disease (GERD), which is one of the most common disorders seen by general practitioners and gastroenterologists in Europe [5]. GERD prevalence estimates range from 18 to $28 \%$ in North America and from 9 to $26 \%$ in Europe [6]. Moreover, the incidence appears to be rising and increasingly younger people are affected [7]. The symptoms of GERD can include cough, hoarseness, asthma, dental erosions, chest pain, and sleep disturbances [8].

The most common management strategy for gastritis as well as GERD is reduction of gastric acidity to relieve symptoms and promote repair of the stomach lining. Medications that reduce the amount of acid in the stom- ach include antacids such as aluminum and magnesium salts, $\mathrm{H} 2$ receptor blockers such as famotidine and ranitidine, and proton pump inhibitors (PPIs) such as omeprazole and pantoprazole. PPIs decrease acid production more effectively than $\mathrm{H} 2$ blockers. Although PPIs are generally safe, they can be associated with adverse events such as osteoporosis, community-acquired pneumonia, Clostridium difficile infection [8], alteration of vitamin and mineral absorption, an increased risk of traveler's diarrhea, small intestinal bacterial overgrowth, spontaneous bacterial peritonitis, and interstitial nephritis [9]. Also, a number of patients with GERD fail to respond symptomatically to acid-suppressive therapy. Though PPIs have revolutionized the treatment of GERD and gastritis, there are still unmet medical needs, particularly in the long-term treatment of these diseases.

Gastricumeel (Ga6) is a natural combination medicinal product consisting of six ingredients traditionally used for the treatment of bloating, acid reflux, and other gastritis-related symptoms as well as for heartburn. No clinical trials on Ga6 have been published. Some observational studies used it as an adjuvant medication for peptic ulcer accompanied by dyspeptic symptoms and abdominal pain $[10,11]$, functional dyspepsia [12], and chronic gastritis $[11,13]$. No adverse reactions were reported in these studies, including in pediatric populations $[13,14]$. The majority of these studies included $\mathrm{Ga} 6$ as part of complex protocols with other homeopathic medicinal products and/or with standard conventional treatments. No direct comparison of Ga6 with a standard therapy has been previously investigated.

We opted for an observational, pharmacoepidemiological comparative cohort study because this design includes a patient population that is more representative of day-today clinical practice compared to patients included in randomized trials. This study aimed to compare the effectiveness and safety of Ga6 with PPIs in the treatment of patients with dyspepsia, heartburn, and related symptoms.

\section{Subjects and Methods}

\section{Study Design}

This was a multicenter, prospective, parallel-group, observational, pharmacoepidemiological cohort study. As the study attempted to capture clinical reality, patients were treated in accordance with routine practice and the dosage and duration of treatment were at the discretion of the physician. No specifications as to other medications were made, but additional nonpharmacological measures for the main indication and the use of conventional or nonconventional medication for comorbidities were permitted and recorded in the case forms.

The participating physicians were mainly (80\%) general practitioners from urban and rural areas throughout Germany, the majority of whom used both conventional and alternative medicines. Regardless of specialty, each practitioner had the option of prescribing Ga6 or conventional therapies in each individual case. 


\section{Patient Population}

Adult patients with suspected new or recurring acute or chronic gastritis or heartburn, which the practitioner aimed to treat with PPIs or Ga6 as monotherapy, were eligible. The following exclusion criteria were applied: patients already receiving medication, or requiring additional medication, for their gastritis or heartburn; severe psychiatric disturbances; known abuse of alcohol or drugs; and withdrawal symptoms.

The decision to include a patient in the study was taken at the point of prescription. Patients would be treated either with Ga6 or with PPIs and observed over a maximum period of 6 weeks for a baseline, intermediate, and final examination. This observation schedule is in line with current German [15] and UK [16] guidelines for the management of GERD, which refer to an initial 4-week treatment period.

\section{Study Medication}

Ga6 is a homeopathic medicinal product prepared in accordance with the German Homeopathic Pharmacopoeia. Each 301.5-mg tablet contains $30 \mathrm{mg}$ Argentum nitricum D6, $30 \mathrm{mg}$ Acidum arsenicosum D6, $60 \mathrm{mg}$ Pulsatilla pratensis D4, $60 \mathrm{mg}$ Strychnos nux-vomica D4, $60 \mathrm{mg}$ Carbo vegetabilis D6, $60 \mathrm{mg}$ Stibium sulfuratum nigrum D6, and $1.5 \mathrm{mg}$ Magnesium stearate. The dosage was in accordance with the instructions of the practitioner. The standard manufacturer's recommendations were $3 \times 1$ tablet per day, or up to 12 tablets per day each 30-60 min for acute complaints.

The reference drugs were PPIs in tablet, capsule, or coated tablet form containing active ingredients such as omeprazole, pantoprazole, lansoprazole, or rabeprazole, given in line with the statutory drug information.

\section{Data Collection}

Demographic data, vital parameters, occupation, main diagnosis, course of the disease, dosage of Ga6 or PPIs, concomitant or additional medicinal or nonpharmacological treatments, concomitant diseases plus their treatment if applicable, and the degree and severity of the clinical symptoms were recorded at baseline by the practitioner.

The global patient compliance was rated as very good, good, moderate, poor, or not assessable.

The practitioner assessed effectiveness by rating: (1) the actual degree of illness severity $(0=$ not at all, $1=$ slightly, $2=\bmod$ erately, 3 = definitely, $4=$ severely, 5 = extremely severely); (2) the intensity of the symptoms (acidic) eructation, abdominal fullness/feeling of pressure, pyrosis, nausea, vomiting, abdominal pain, hunger pain, and dysphagia $(0=$ no symptom, $1=$ mild, 2 = moderate, 3 = severe occurrence of symptoms); (3) the global assessment of the therapy at the end of observation as follows: first improvement of symptoms (yes/no), time of occurrence of first improvement (within $24 \mathrm{~h}$, after 2 days, after 3 days, after 4-7 days, after 8-14 days, after $>14$ days, no improvement; (4) the change of overall condition compared to baseline (very much better, much better, slightly better, unchanged, slightly worse, much worse, very much worse, not assessable); and (5) the therapeutic effectiveness (very good, good, satisfactory, no improvement, worsened, not assessable).

At the 3-week (if applicable) and 6-week visit, any improvement of symptoms, time of first improvement, compliance, changes in treatment(s) (if applicable), ability to work, and duration of work absence (if applicable) was assessed.

The analysis of safety criteria was based on the overall assessment of tolerability as well as on the occurrence of adverse events. Tolerability was assessed on the following scale: very good (no symptoms of intolerance), good (occasional occurrence of symp- toms of intolerance), moderate (frequent occurrence of symptoms of intolerance), poor (occurrence of symptoms of intolerance after each medicine administration), or not assessable.

The documentation of the therapy dates took place via use of electronic data capture by the investigator, and data entry took place in an electronic case report form.

\section{Statistical Analysis}

Summary statistics were calculated using absolute and percent number of ratings. Differences in baseline characteristics between treatment groups were adjusted for by propensity analysis [17]. Adjustment for determinants of outcome was achieved by estimating a propensity score for each patient using logistic regression and subsequently dividing and analyzing patients in five approximately equal propensity score strata (quintiles) [18]. Between-group differences were evaluated using ANOVA, Cochran-Mantel-Haenszel test, and Fisher's exact test as appropriate. Adjusted two-sided 95\% CIs were calculated for all comparisons and noninferiority analyses were carried out for the intensity score of each of the individual symptoms. To fulfill the requirement for noninferiority, the lower bound of the 95\% CI needed to include the value zero (otherwise Ga6 would be superior to PPIs), but not cross the inferiority bound. In the absence of available literature, this inferiority bound was pragmatically set at $10 \%$ of the intensity score range $(0-3$ scale points), therefore 0.3 points. The inferiority bound for the mean difference in the symptom score change between the Ga6 and PPI groups (Ga6 minus PPI, a negative difference implying a larger symptom reduction in the PPI group) was set at -0.3 . There was no predefined primary outcome measure; analyses were therefore principally exploratory in character.

Since patients with any missing value for any of the criteria involved in the propensity score classification procedure would not be taken into account, nominally scaled data were reduced to one single characteristic and for each criterion (e.g., "female yes/ no") missing values were subsummarized as "no." For criteria rating scales and interval scaled data (e.g., age, height) an own class "missing" was created for each criterion.

Mean scores were calculated for symptom scores and summarized by arithmetic means, standard deviation, median, minimum, maximum, as well as first and third quartile. Within-group differences were calculated between the intermediate and final examination compared to baseline. Effect measures for differences between groups were presented using the differences in the mean score reduction at the intermediate and final examination.

Global assessments (time to first improvement, compliance, change of condition, and therapeutic efficacy) are presented with absolute and relative numbers of frequency, and for all relevant measures two-sided 95\% confidence limits were calculated. In order to control the influence of unbalanced baseline characteristics on the assessment of treatment effectiveness, all analyses were stratified according to the classes of the propensity score. An analysis without any stratification was performed to assess the robustness of analyses.

The analysis of safety criteria was based on the overall assessment of tolerability (very good, good, moderate, poor, not assessable) as well as on the occurrence of adverse events.

Patients who terminated treatment prematurely but who were present at final examination were included in the safety and effectiveness analyses.

Data analysis was performed with SAS version 9.1. 


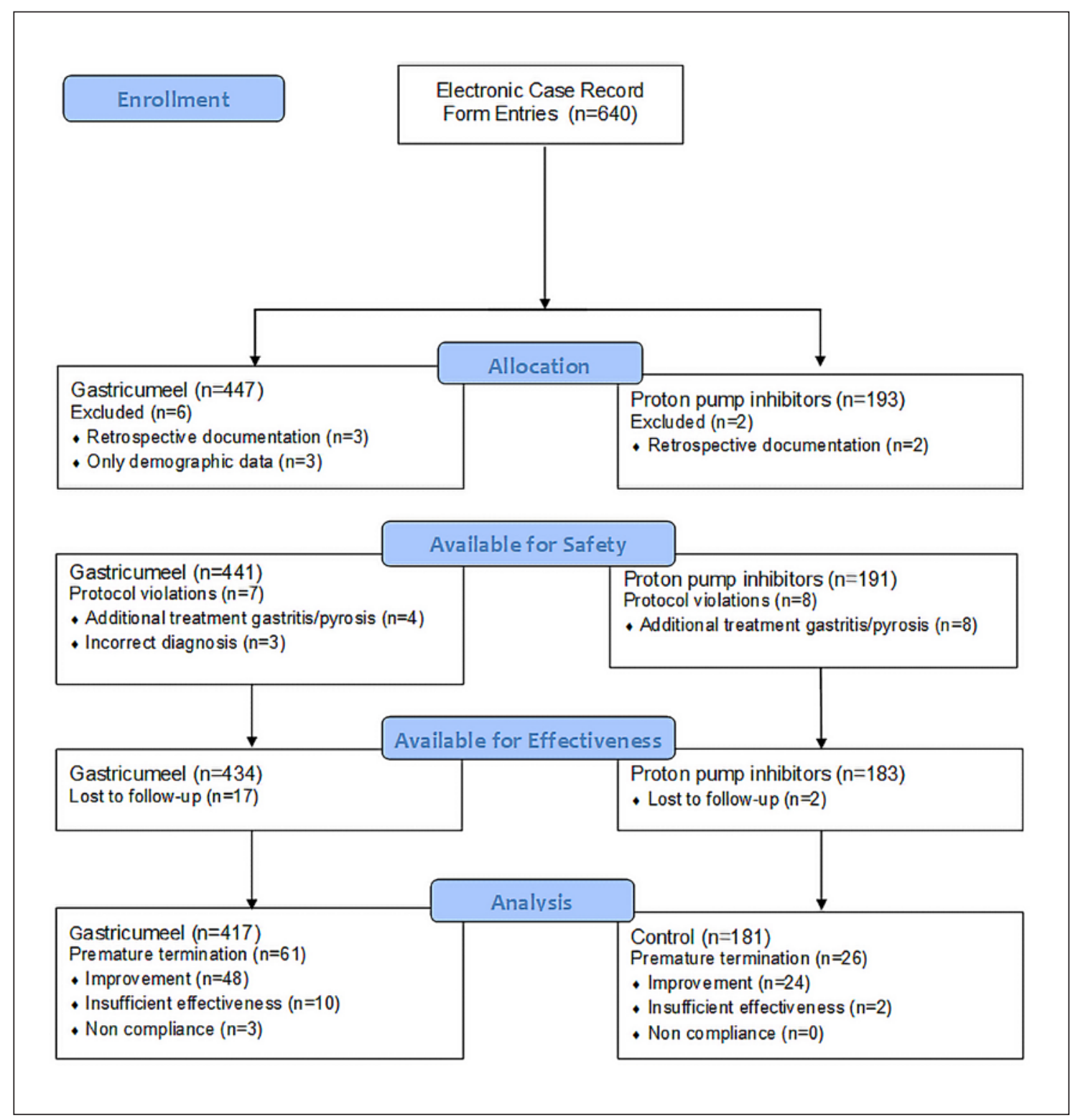

Fig. 1. Participant flow.

\section{Results}

\section{Study Population}

The study was conducted in 48 doctors' practices in Germany from April to December 2006.

Electronic case report form entries for 640 patients were made. The subsequent flow of participants in the study is given in Figure 1. Three patients in the Ga6 group were excluded from the safety analysis because only demographic data were documented. Five additional patients were excluded from any analysis because the documentation was retrospective and therefore not reliable. In total, 632 (Ga6 441, PPI 191) patients were included in the safety analysis and 617 (Ga6 434, PPI 183) patients in the effectiveness analysis.
The mean duration of observation was 43 days for patients treated with $\mathrm{Ga} 6$ and 39 days for patients treated with PPIs. Eighty-seven patients in the effectiveness population with data available for analysis discontinued the treatment prematurely (61 [14.6\%] in the Ga6 group and 26 [14.3\%] in the PPI group). The main reason for discontinuation was definite improvement of symptoms/remission (48 [11.5\%] in the Ga6 group and 24 [13.2\%] in the PPI group). Insufficient efficacy of treatment was the reason for discontinuation in 10 (2.4\%) of patients of the Ga6 group and 2 (1.1\%) patients in the PPI group.

Demographic, clinical, and other relevant characteristics are given in Table 1 . In the Ga6 group $67.3 \%$ were female versus $57.4 \%$ females in the PPI group, indicating a higher percentage in the Ga6 group. The mean age and 
Table 1. Comparison of demographic, clinical, and other relevant characteristics

\begin{tabular}{|c|c|c|c|}
\hline Characteristics & Ga6 group & PPI group & $p$ value \\
\hline Number patients & 434 & 183 & \\
\hline Age, years & $43.3(22.1)$ & $51.1(16.3)$ & $<0.0001$ \\
\hline Sex, men:women & $142: 292$ & $78: 105$ & 0.0215 \\
\hline $\mathrm{BMI}, \mathrm{kg} / \mathrm{m}^{2}$ & $23.5(4.4)$ & $25.4(4.5)$ & $<0.0001$ \\
\hline Diagnosis $^{1}$ & & & ns \\
\hline Acute gastritis & $252(58.1 \%)$ & $105(57.4 \%)$ & \\
\hline Chronic gastritis & $93(21.4 \%)$ & $47(25.7 \%)$ & \\
\hline Heartburn & $172(39.6 \%)$ & $83(45.4 \%)$ & \\
\hline Other & $20(4.6 \%)$ & $4(2.2 \%)$ & \\
\hline Course of disease $e^{1}$ & & & ns \\
\hline Acute & $296(68.2 \%)$ & $114(62.3 \%)$ & \\
\hline Chronic & $79(18.2 \%)$ & $30(16.4 \%)$ & \\
\hline Recurrent & $96(22.1 \%)$ & $50(27.3 \%)$ & \\
\hline Type of previous therapy in chronic/relapsing disease ${ }^{1}$ & 144 & 75 & $\mathrm{~ns}$ \\
\hline Medicinal & $74(51.4 \%)$ & $43(57.3 \%)$ & \\
\hline Nonmedicinal & $34(23.6 \%)$ & $12(16.0 \%)$ & \\
\hline No therapy & $41(28.5 \%)$ & $20(26.7 \%)$ & \\
\hline Duration of disease in weeks & $2.0(0.1,8.7)$ & $2.0(0.2,8.7)$ & ns \\
\hline Degree of severity/illness & & & $<0.0001$ \\
\hline Slightly ill & $66(15.2 \%)$ & $13(7.1 \%)$ & \\
\hline Moderately ill & $222(51.2 \%)$ & $63(34.4 \%)$ & \\
\hline Definitely ill & $135(31.1 \%)$ & $94(51.4 \%)$ & \\
\hline Severely ill & $11(2.5 \%)$ & $13(7.1 \%)$ & \\
\hline Clinically relevant concomitant disease (yes:no) & $109: 325$ & $55: 128$ & ns \\
\hline Additional medicines for concomitant disease (yes:no) & $73: 361$ & $41: 142$ & ns \\
\hline Nonmedicinal treatment for concomitant disease (yes:no) & 20:414 & $10: 173$ & ns \\
\hline Additional medicines for gastritis/heartburn (yes:no) & $3: 431$ & $0: 183$ & ns \\
\hline Nonmedicinal treatment for gastritis/heartburn (yes:no) & $47: 387$ & $5: 187$ & 0.0007 \\
\hline Patient active at work (yes:no) & $215: 219$ & $102: 81$ & ns \\
\hline Patients active professionally given sick note (yes:no) & $75: 140$ & $30: 72$ & ns \\
\hline
\end{tabular}

Values are given as mean (standard deviation), $n(\%)$, or median (quartile 1, quartile 3). Ga6, Gastricumeel; ns, not significant; PPI, proton pump inhibitor. ${ }^{1}$ More than one category per patient is possible.

BMI of the patients in the Ga6 group was significantly lower than in the PPI group.

The most frequent diagnosis was acute gastritis, followed by the symptom of heartburn. The course of disease was most commonly acute, and the type of previous therapy did not differ significantly between the groups. The diagnosis was mainly based on clinical symptomatology (93\%) and/or palpation (61\%) and less commonly on endoscopy (25\%). The $75 \%$ of patients who did not have an endoscopy therefore had the diagnosis "dyspepsia or suspected gastritis."

The average duration of the disease was comparable between the treatment groups, but the range varied widely (Ga6, 0-520 weeks; PPIs, 0-780 weeks).

In total, 317 patients were active professionally; $75 \mathrm{pa}-$ tients (34.9\%) in the Ga6 group and 30 patients (29.5\%) in the PPI group received a sick note.

The percentage of patients who showed mild and moderate symptoms of the disease was higher in the Ga6 group (66.4\%) than in the control group (41.5\%), and in- versely the prevalence of severe symptoms was higher in the PPI group (59.1\%) than in the Ga6 group (33.6\%).

\section{Treatment}

A total of 190 patients (43.8\%) were treated with a regular daily dosage of $3 \times 1$ tablets; 1 patient took $1 \times 3$ tablets a day. Eight patients (1.8\%) took a daily dosage of $<3$ tablets and the other 236 patients $(54.4 \%)$ took $>3$ tablets a day. At the final examination the changes in dosage were documented in 98 cases - in 7 cases dosage was increased and in 91 cases it was reduced. The most frequently used PPIs were omeprazole (47.5\%), pantoprazole $(24.0 \%)$, esomeprazole (16.9\%), and lansoprazole (8.2\%). Dosages varied, the most common daily dosages at baseline being $1 \times 20 \mathrm{mg}(41.5 \%), 1 \times 40 \mathrm{mg}(20.8 \%)$, and $2 \times 20 \mathrm{mg}(18.0 \%)$. At the final examination, changes were reported in 38 cases - in 2 cases dosage was increased and in 36 cases dosage was reduced.

An additional medicinal therapy for the gastritis or heartburn was given to 3 patients in the Ga6 group: $\mathrm{Mu}$ - 
Fig. 2. Reduction average symptom scores at final examination compared to baseline with 95\% CIs, adjusted for the propensity scores and baseline values.
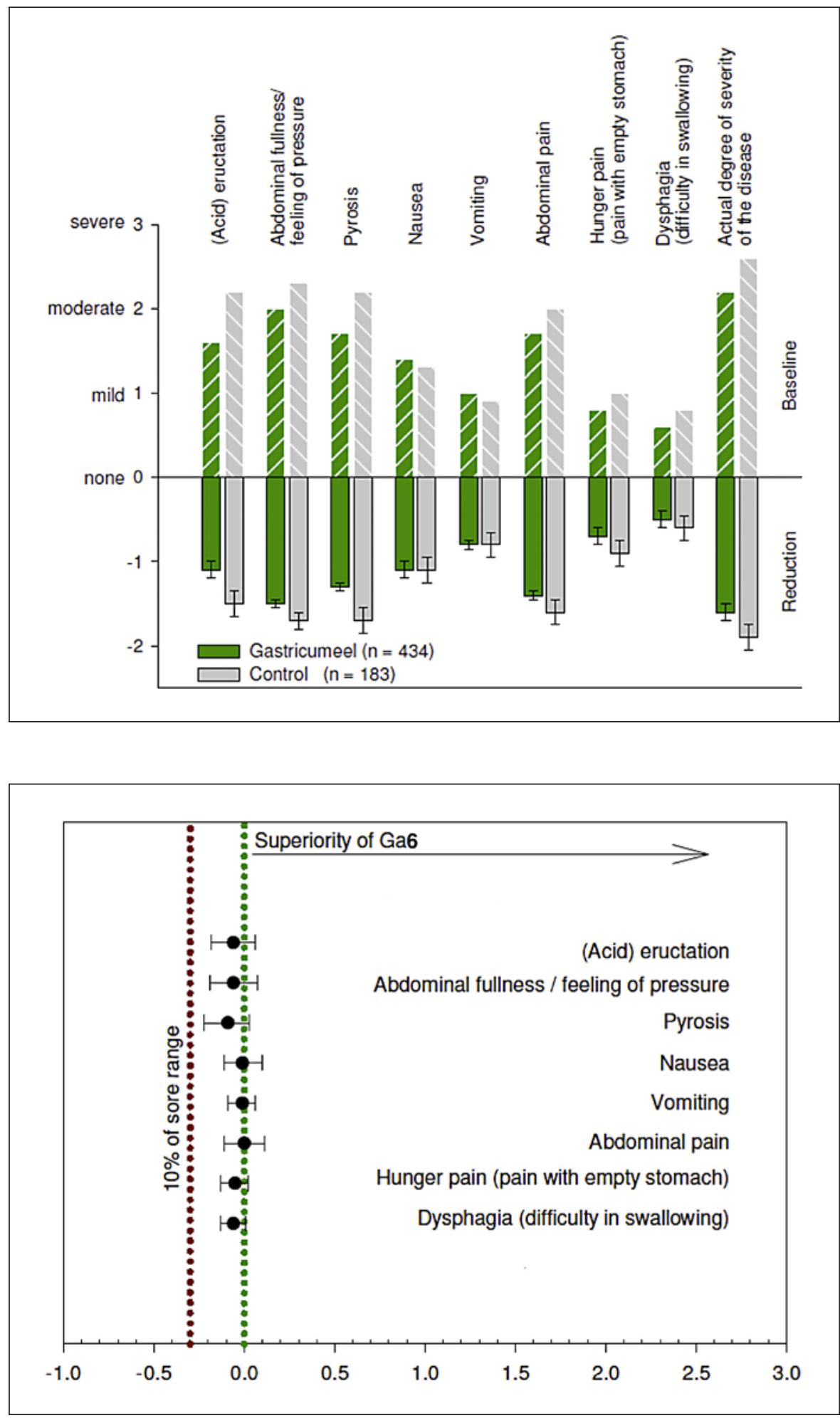

Fig. 3. Propensity score- and baseline value-adjusted differences in mean symptom intensity scores, with $95 \%$ CIs. The red dotted line indicates the value below which Ga6 has inferior effectiveness compared to PPIs. Ga6, Gastricumeel; PPIs, proton pump inhibitors. cofalk (laxative), Pulsatilla (for the psychological component), and Imodium (antidiarrheal). These patients therefore did not formally meet the inclusion criteria, but since there was no influence on the effectiveness analyses, it was decided to keep these patients in the study.

Nonpharmacological treatment of the gastritis or heartburn was more common in the Ga6 group (24\%) than in the PPI group (4\%). In most cases a special diet was recommended. Clinically relevant concomitant diseases were recorded in 109 (25\%) patients in the Ga6 group and in 55 (30\%) patients in the PPI group, primarily essential hypertension, diabetes mellitus, and chronic ischemic heart disease. 


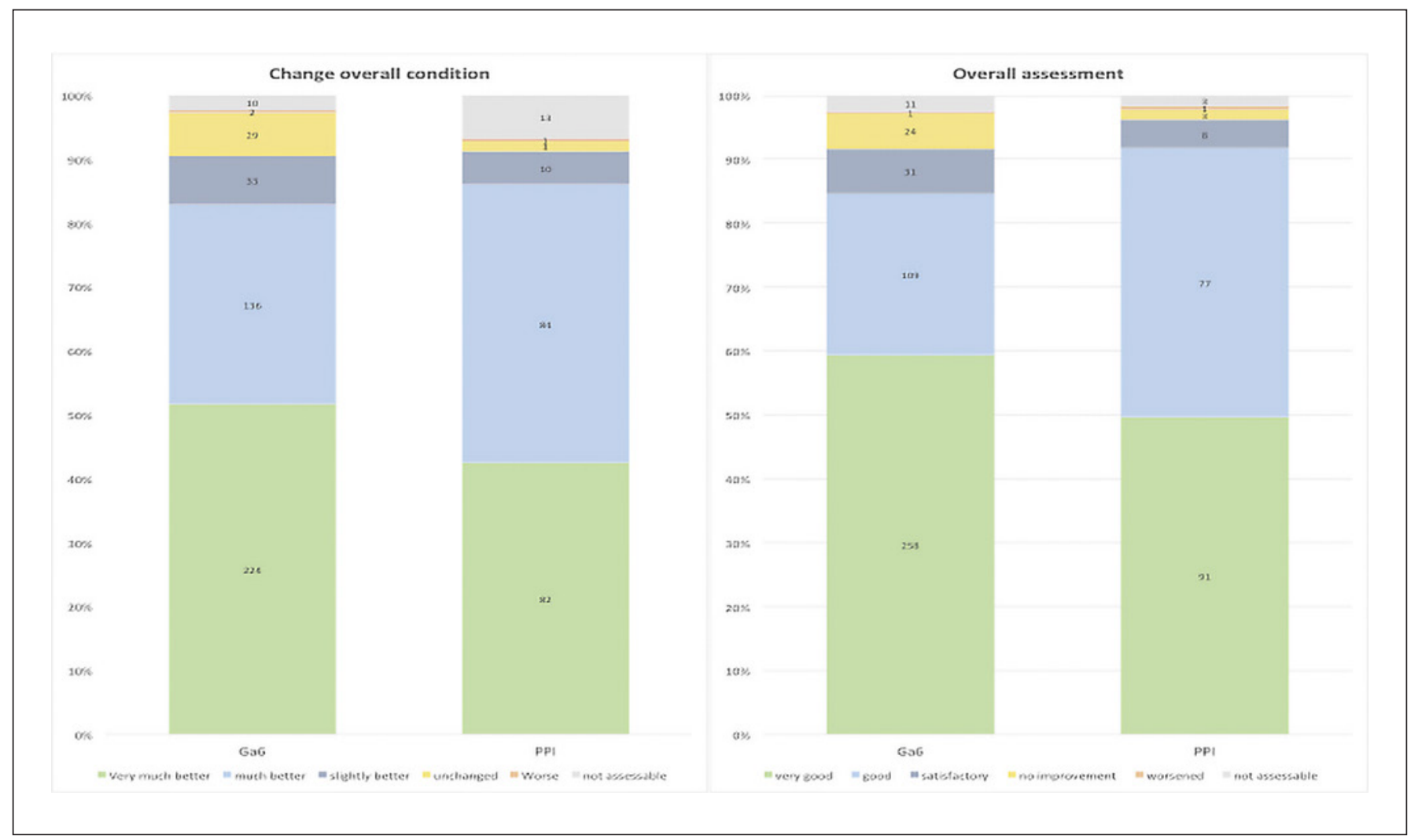

Fig. 4. Assessment of change in overall condition and overall effectiveness at the end of the observation period. The numbers of patients in each category are given in the bars and the $x$ axis indicates the percentages. Ga6, Gastricumeel; PPI, proton pump inhibitor.

\section{Outcome Assessment}

There were significant differences between the two treatment groups in several demographic and clinical variables at baseline (Table 1). Also, the final examination varied significantly from the originally planned maximum observation period of 6 weeks. For the purpose of the propensity score analysis, control dates were additionally classified into four categories $(<5$ weeks, $5-7$ weeks, $>7$ weeks, at the time of last individual observation) and analyzed accordingly. After adjusting the baseline criteria on the basis of stratification into the five propensity score strata, the between-group $p$ values for all criteria were $>0.05$. The most important influencing factors were symptom severity, weight, nonmedical additional treatment, complaints after coffee consumption, adverse events, and excessive eating.

The adjusted reductions in the symptom scores at the end of the observation period compared to baseline in both treatment groups are given in Figure 2. The adjusted reduction in the overall symptom score was 8.6 (95\% CI 8.2-9.0) in the Ga6 group compared to 10.0 (95\% CI 9.310.6) in the PPI group. None of the between-group differences in symptom scores were statistically significant.

Between-group differences in the change in symptom scores at the end of observation, adjusted for the propen- sity score and the baseline symptom scores are given in Figure 3. This figure illustrates that for all eight symptoms the lower bound of the $95 \%$ CIs remained well within the noninferiority bound.

An improvement of symptoms was seen in $88.7 \%$ of patients in the Ga6 group and in $93.4 \%$ of patients in the PPI group at the end of treatment. This improvement was apparent within the first day of treatment in $5.3 \%$ of patients in the Ga6 group compared to $10.4 \%$ in the PPI group. Within 7 days the improvement was apparent in $42.6 \%$ of Ga6 patients compared to $58.5 \%$ of PPI patients, indicating a faster onset of first improvement of symptoms in the PPI group $(p<0.0001)$.

Seventy-three of the 75 working patients in the Ga6 group on sick leave at baseline were able to return to work at the end of treatment, compared to 28 of the 30 patients on sick leave in the PPI group (nonsignificant; $p>0.05$ ).

The assessment of the change in overall condition, overall effectiveness, patient compliance, and tolerability are given in Figures 4 and 5. Figure 4 indicates that the change in overall condition was assessed as "very much better" or "better" in $83 \%$ of Ga6-treated patients compared to $86 \%$ of PPI-treated patients. The overall assessment of effectiveness of the therapy was rated as "good" or "very good" in the great majority of patients in both 


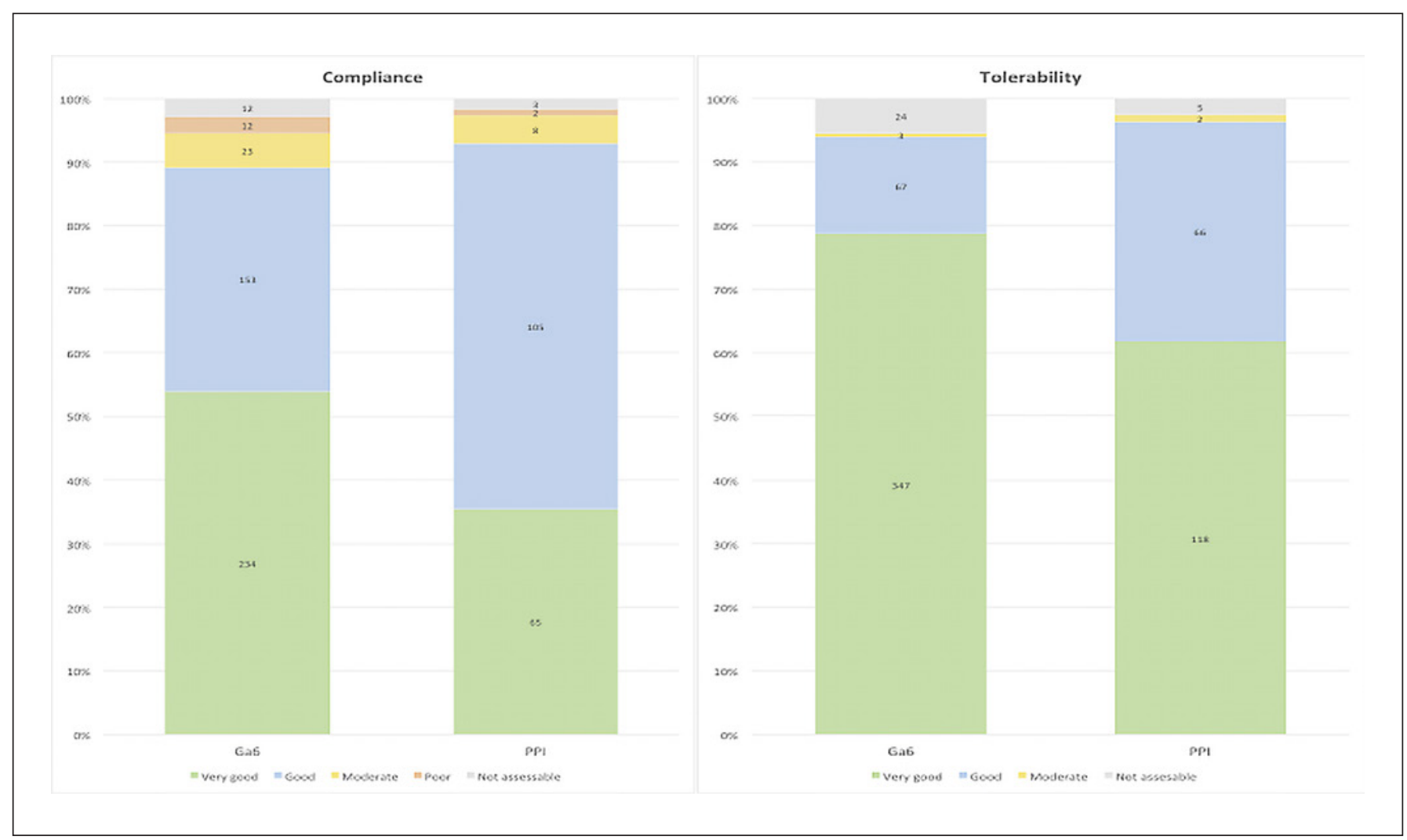

Fig. 5. Assessment of treatment compliance and tolerability at the end of the observation period. The numbers of patients in each category are given in the bars and the $x$ axis indicates the percentages. Ga6, Gastricumeel; PPI, proton pump inhibitor.

treatment groups. Figure 5 illustrates that the patient compliance was rated as "very good" in a significantly higher percentage of Ga6 patients (54\%) compared to PPI patients $(36 \%)(p=0.0017)$. Also, the tolerability of the therapy was rated as "very good" more often in the Ga6 group (79\%) compared to the PPI group $(62 \%)(p<$ $0.0001)$. The latter is unsurprising because good tolerability is likely to be related to better compliance. There were no adverse drug reactions reported in either treatment group.

\section{Discussion/Conclusion}

This comparative study addressed the use of Ga6 in the treatment of suspected gastritis and heartburn in general practice. The results indicate that Ga6, either as monotherapy or in combination with nonpharmacological treatments such as diets, is noninferior to PPIs. Whilst the onset of action was quicker in PPIs, treatment compliance and tolerability were reported to be better on Ga6.

A strength of this study is that it included a population more representative of the wide variety of patients who opt for integrative therapies in routine practice, compared to populations enrolled in randomized trials. This was the first large-scale clinical study on the use of Ga6 in routine clinical practice which substantially adds to the published observational research.

A limitation of this study is related to its nonexperimental nature: although detailed diagnostic, clinical, and anamnestic data were collected and used for statistical adjustment of the outcome measures, this does not guarantee that all relevant variables were assessed and adjusted for. This could for instance have included lifestyle changes such as diet which are known to alleviate dyspepsia and heartburn symptoms. Another limitation was that in the majority of the patients, the diagnosis of gastritis was not endoscopically confirmed. So whilst on the basis of the symptom picture there is likely to be a significant overlap with gastritis, this study did not specifically investigate the effectiveness in gastritis.

A weakness was the assessment of the patients' symptom severity based on questioning by the practitioner. An independent assessment by the patients themselves would most likely have given a more reliable estimate. Also, the absence of a validated outcome measure led to the relatively arbitrary choice of the noninferiority threshold. The observed 95\% CIs for between-treatment differences in this study did not exceed 0.15 score points, which corresponds to a standardized effect size (also referred to as 
“Cohen's d" [19]) of 0.28, corresponding to a "small" effect size. The CIs in this study were therefore sufficiently narrow to exclude the actual presence of a small to moderate difference, which further substantiates the conclusion of a noninferior treatment effect.

PPIs are effective and generally have a good safety profile [20], and this was also confirmed in this study with a short follow-up. However, the use of these drugs is not entirely without side effects. The risk of community-acquired pneumonia is slightly increased [21]; whilst rare, immediate life-threatening reactions - including anaphylaxis - have been increasingly reported [22]. Also, the risk of hip fractures is increased [23], which can be a problem with long-term use in the elderly. PPIs are also associated with both acute and chronic renal diseases [24]. In conclusion, particularly prolonged use of PPIs is associated with minor and also potentially major adverse health outcomes [25].

Whilst treatment guidelines clearly recommend not using antacids for long periods [16], withdrawal of PPIs has been demonstrated to cause rebound hyperacidity even after short periods of use $[26,27]$. This makes many patients experience a worsening of symptoms after withdrawal. In primary care, failure rates between 73 and $86 \%$ have been reported in association with abrupt withdrawal $[28,29]$. This problem is compounded by the widespread overprescription of PPIs [30]. Apart from being a possible alternative to PPIs, Ga6 has a potential role to play in supporting patients who find it difficult to withdraw from PPIs. The latter would be a potentially fruitful area for further research.

This study informs physicians about the effectiveness and safety of Ga6 in patients with dyspepsia and/or heartburn. The results suggest that it is worth considering Ga6 as a safe and effective treatment option in the management of dyspepsia and heartburn.

\section{Acknowledgment}

The authors wish to thank P. Klein for assistance with the statistical analysis and R. Gottwald for writing the clinical study report.

\section{Statement of Ethics}

Due to observational nature of the study, obtaining approval from an ethics committee was not required. The study was conducted in accordance with Good Epidemiological Practice and the Declaration of Helsinki and in accordance with German regulations as detailed in Empfehlungen zur Planung, Durchführung und Auswertung von Anwendungsbeobachtungen vom 12.11.1998 (Bundesanzeiger Nr. 229 vom 4.12.1998). According to $\$ 67(6)$ of the German drug law, the study was notified to the Kassenärztliche Bundesvereinigung and the Bundesinstitut für Arzneimittel und Medizinprodukte. Full confidentiality of patient data was ensured.

\section{Conflict of Interest Statement}

R. van Haselen is a former employee of Heel and was involved in the study at the time. K. Cesnulevicius is an employee of Heel.

\section{Funding Sources}

This study was financially supported by Heel.

\section{Author Contributions}

R. van Haselen was involved in the conduct, analysis, and writing of the article. K. Cesnulevicius was involved in the planning, analysis, and writing of the article.

\section{References}

1 National Institute of Diabetes and Digestive and Kidney Diseases (NIDDK). Gastritis \& Gastropathy. https://www.niddk.nih.gov/ health-information/digestive-diseases/gastritis-gastropathy [accessed November 5, 2020].

2 Aziz I, Palsson OS, Törnblom H, Sperber AD, Whitehead WE, Simrén M. Epidemiology, clinical characteristics, and associations for symptom-based Rome IV functional dyspepsia in adults in the USA, Canada, and the UK: a crosssectional population-based study. Lancet Gastroenterol Hepatol. 2018 Apr;3(4):252-62.

3 Talley NJ, Ford AC. Functional Dyspepsia. N Engl J Med. 2015 Nov;373(19):1853-63.

4 Suzuki H, Hibi T. Overlap syndrome of functional dyspepsia and irritable bowel syndrome - are both diseases mutually exclusive? J Neurogastroenterol Motil. 2011 Oct;17(4): 360-5.
5 Bruley des Varannes S, Cestari R, Usova L, Triantafyllou K, Alvarez Sanchez A, Keim S, et al. Classification of adults suffering from typical gastroesophageal reflux disease symptoms: contribution of latent class analysis in a European observational study. BMC Gastroenterol. 2014 Jun;14(1):112.

6 El-Serag HB, Sweet S, Winchester CC, Dent J. Update on the epidemiology of gastro-oesophageal reflux disease: a systematic review. Gut. 2014 Jun;63(6):871-80.

7 Yamasaki T, Hemond C, Eisa M, Ganocy S, Fass R. The changing epidemiology of gastroesophageal reflux disease: are patients getting younger? J Neurogastroenterol Motil. 2018 Oct;24(4):559-69.

8 Vakil N, Van Zanten SV, Kahrilas P, Dent J, Jones R; Global Consensus Group. The Montreal definition and classification of gastro- esophageal reflux disease: A global evidencebased consensus. Am J Gastroenterol. 2006 Aug;101(8):1900-20; quiz 1943.

9 Johnson DA, Oldfield EC 4th. Reported side effects and complications of long-term proton pump inhibitor use: dissecting the evidence. Clin Gastroenterol Hepatol. 2013 May; 11(5):458-64.

10 Mukhina YG, Ilyenko LI, Rura EA. Potentialities of remedies of natural origin used to treat ulcerous lesion of upper portion of digestive tract. Russ J Child Infect. 2007;6:5560. Russian.

11 Lukin M. Antihomotoxic therapy of duodenal peptic ulcer and chronic gastritis. Medyc Biol. 2002;1:9-14. Polish.

12 Ricken KH. Clinical treatment of functional dyspepsia and Helicobacter pylori gastritis. Biomed Ther. 1997;15(3):76-81. 
13 Khmelevskaya AV. Gastricumeel in the treatment of chronic gastritis. Biol Ther (Ukraine). 1998;1:39. Russian.

14 Mukhina YG, Ilienko LI, Rura EA. Potential of natural products-derived drugs in the treatment of peptic ulcer diseases in children. Pediatr (Moscow). 2007;86:130-1. Russian.

15 Koop H, Fuchs KH, Labenz J, Lynen Jansen P, Messmann H, Miehlke S, et al. S2k-Guideline 021/013 GERD [S2k-Leitlinie 021/013 Gastroösophageale Refluxkrankheit]. Available from: www.awmf.org/uploads/tx_szleitlinien/ 021-013l_S2k_Refluxkrankheit_2014-05-abgelaufen.pdf.

16 National Institute for Health and Care Excellence (NICE). Indigestion, heartburn and reflux in adults. Available from: www.nice.org. uk/guidance/cg184/resources/indigestionheartburn-and-reflux-in-adults-pdf250345039813 [accessed March 19, 2020].

17 Rosenbaum P, Rubin DB. The central role of the propensity score in observational studies for causal effects. Biometrika. 1983;70(1):4155.

18 Liang KY, Zeger SL. Longitudinal data analysis using generalized linear models. Biometrika. 1986;73(1):13-22.
19 Cohen J. Statistical Power Analysis for the Behavioral Sciences. 2nd ed. USA: Lawrence Erlbaum Associates; 1988.

20 Thomson AB, Sauve MD, Kassam N, Kamitakahara H. Safety of the long-term use of proton pump inhibitors. World J Gastroenterol. 2010 May;16(19):2323-30.

21 Rodríguez LA, Ruigómez A, Wallander MA, Johansson S. Acid-suppressive drugs and community-acquired pneumonia. Epidemiology. 2009 Nov;20(6):800-6.

22 Casciaro M, Navarra M, Inferrera G, Liotta M, Gangemi S, Minciullo PL. PPI adverse drugs reactions: a retrospective study. Clin $\mathrm{Mol} \mathrm{Al-}$ lergy. 2019 Jan;17(1):1.

23 Poly TN, Islam MM, Yang HC, Wu CC, Li YJ. Proton pump inhibitors and risk of hip fracture: a meta-analysis of observational studies. Osteoporos Int. 2019 Jan;30(1):103-14.

24 Al-Aly Z, Maddukuri G, Xie Y. Proton Pump Inhibitors and the Kidney: Implications of Current Evidence for Clinical Practice and When and How to Deprescribe. Am J Kidney Dis. 2020 Apr;75(4):497-507.

25 Islam MM, Poly TN, Walther BA, Dubey NK, Anggraini Ningrum DN, Shabbir SA, et al. Adverse outcomes of long-term use of proton pump inhibitors: a systematic review and meta-analysis. Eur J Gastroenterol Hepatol. 2018 Dec;30(12):1395-405.
26 Niklasson A, Lindström L, Simrén M, Lindberg G, Björnsson E. Dyspeptic symptom development after discontinuation of a proton pump inhibitor: a double-blind placebo-controlled trial. Am J Gastroenterol. $2010 \mathrm{Jul}$; 105(7):1531-7.

27 Reimer C, Søndergaard B, Hilsted L, Bytzer P. Proton-pump inhibitor therapy induces acidrelated symptoms in healthy volunteers after withdrawal of therapy. Gastroenterology. 2009 Jul;137(1):80-7.

28 Zwisler JE, Jarbøl DE, Lassen AT, Kragstrup J, Thorsgaard N, Schaffalitzky de Muckadell OB. Placebo-controlled discontinuation of long-term acid-suppressant therapy: a randomised trial in general practice. Int J Family Med. 2015;2015:175436.

29 Reimer C, Bytzer P. Discontinuation of longterm proton pump inhibitor therapy in primary care patients: a randomized placebocontrolled trial in patients with symptom relapse. Eur J Gastroenterol Hepatol. 2010 Oct; 22(10):1182-8

30 Forgacs I, Loganayagam A. Overprescribing proton pump inhibitors. BMJ. 2008 Jan; 336(7634):2-3 